\title{
CAPÍTULO 11: CONHECIMENTO DOS GESTORES DE UM DOS CAMPUS DO INSTITUTO FEDERAL DE EDUCAÇÃO, CIÊNCIA E TECNOLOGIA DE PERNAMBUCO SOBRE NOÇÕES DE EMPREENDEDORISMO
}

\author{
CAPÍTULO 11: CONOCIMIENTO DE LOS GERENTES DE CAMPUS DE \\ INSTITUTO FEDERAL DE EDUCACIÓN, CIENCIA Y TECNOLOGIA DE \\ PERNAMBUCO A RESPECTO DE NOCIONES DE EMPRENDIMIENTOS
}

\section{CHAPTER 11: KNOWLEDGE OF MANAGERS OF A INSTITUTO FEDERAL DE EDUCAÇÃO, CIÊNCIA E TECNOLOGIA DE PERNAMBUCO CAMPUS ABOUT NOTIONS OF ENTREPRENEURSHIP}

Kleber Danylo Mendes da Silva ${ }^{1}$; Guilherme de Siqueira Freitas Pontes ${ }^{2}$; Simone de Paula Silva ${ }^{3}$; Erick Viana da Silva $^{4}$

DOI : https://doi.org/10.31692/978-65-88970-03-4.174-187

\begin{abstract}
RESUMO
O presente estudo teve como objetivo o entendimento do fenômeno de práticas empreendedoras no Instituto Federal de Educação, Ciência e Tecnologia de Pernambuco - Campus Vitória de Santo Antão. Os protagonistas do estudo foram os gestores da instituição de ensino em questão. A temática norteadora visou a descoberta de novos horizontes, por meio de métodos qualitativos e quantitativos no tocante ao conhecimento desses gestores acerca de fenômenos como o empreendedorismo e as empresas juniores, além de compreender as possíveis ações empreendedoras no local de ensino. Ademais, buscou-se compreender quem era esta persona, através da coleta de dados pessoais como sexo biológico e etnia. No que concerne ao desenvolvimento da pesquisa bibliográ*fica a respeito dos assuntos estudados, tal projeto aprofundou-se em leituras de alguns autores de relevância reconhecida sobre a temática. Desta forma, por meio da aplicação a partir da aplicação de métodos inovadores para a educação brasileira, isto é, com a tríade ensino, pesquisa e extensão, que representa a função social das universidades estatais brasileiras. É válido também o resgate das experiências estrangeiras com empresa juniores, bem como uma importante instituição brasileira de fomento e desenvolvimento às ações empreendedoras, tal como o Serviço Brasileiro de Apoio às Micro e Pequenas Empresas, SEBRAE. A necessidade do conhecimento gerado neste estudo é de suma validade, já que, a partir de uma perspectiva recorrente no ensino brasileiro, a educação é uma ferramenta aliada ao desenvolvimento social. Assim, entender as diversas metodologias empreendedoras de educação e a visão daqueles que tomam as decisões no cotidiano deve ser de interesse público.

Palavras-chave: Empreendedorismo, Empresa Júnior, Educação Empreendedora.
\end{abstract}

\section{RESUMEN:}

El presente artículo tuvo como objeto de estudio el entendimiento del fenómeno de prácticas emprendedoras en un campus agrario de Instituto Federal de Educação, Ciência e Tecnologia de Pernambuco. Los protagonistas del estudio fueron los gerentes de esta institución de enseñanza. La temática principal apuntó al descubrimiento de nuevos horizontes por medio de métodos cualitativos y cuantitativos a respecto del conocimiento de estos gerentes sobre los fenómenos como los emprendimientos y las empresas juniores, además de comprender las posibles acciones emprendedoras en el local de enseñanza. Además, se buscó entender quién era esta persona, mediante de la recolección de datos personales, como el sexo biológico y la etnia. En lo que preocupa al desarrollo de la investigación bibliográfica a pesar de los asuntos estudiados, tal proyecto se profundizó en lecturas de algunos escritores de relevancia conocida sobre la temática. De esto modo, a partir de la aplicación

${ }^{1}$ Análise de Desenvolvimento e Sistemas, Instituto Federal de Pernambuco, kdms@ discente

${ }^{2}$ Gestão de Turismo, Instituto Federal de Pernambuco, guilhermesfpontes@ gmail.com

${ }^{3}$ Mestra em Gestão Ambiental, Instituto Federal de Pernambuco, simonedypaula

${ }^{4}$ Mestre em Administração, Instituto Federal de Pernambuco, erick.viana@ recife.ifpe.edu.br 
de métodos innovadores para la educación brasileña, o sea, con la tríade enseñanza, investigación y extensión, que representa la función social de las universidades del estado brasileño. Es válido también el rescate de las experiencias exteriores con empresas juniores, bien como una importante institución brasileña de fomento al desarrollo de acciones emprendedoras, tal como el Servicio Brasileño de Apoyo a las Micro y Pequeñas Empresas (SEBRAE). La necesidad del conocimiento generado en este estudio es de gran validad, ya que, por una perspectiva recurrente en la enseñanza brasileña, la educación es una herramienta aliada al desarrollo social. Así, entender las diversas metodologías emprendedoras de educación y la visión de aquellos que toman las decisiones en el cotidiano debe ser de interés público.

Palabras-clave: Empreendimientos, Empresa Júnior, Educación Emprendedora.

\section{ABSTRACT}

This present article had as study object the comprehension of the phenomenon of entrepreneurship practices in an agriculture campus of Insituto Federal de Educação, Ciência e Tecnologia de Pernambuco. The protagonists of this study were the manager of this related school. The main theme was the discovery of new horizon, by qualitative and quantitative method according to the knowledge of these managers about some phenomenon as entrepreneurship and junior companies, beyond the comprehension of possible entrepreneurship actions in some learning places. Moreover, it was tried to understand who was this person, through the personal data collect, like biological sex and ethnic groups. Concerned to the bibliographical research development related to these subject which were studied, the project deep itself in lectures of relevant and famous authors about these themes. This way, using the application of innovative methods for Brazilian education, it means, the triad teaching, research and extension, which represents the social fu*nction of Brazilian public universities. It's also valid the rescue of foreigners experiences with junior companies, as well an important Brazilian institution, which helps with the development of entrepreneurship actions, for example Brazilian Service of Support to Micro and Small Companies, SEBRAE, in Portuguese. The need of the generated knowledge in this study is pretty valid, once, since a recurrent perspective of Brazilian learning, the education is an ally tool to get social development. This way, understand the diverse entrepreneur methodologies related to education and the view of those who take decision in the daily routine must be part of public interest.

Keywords: Entrepreneurship, Junior Company, Entrepreneur Education

\section{INTRODUÇÃO}

$\mathrm{O}$ artigo possui um referencial teórico que retrata o empreendedorismo, desde sua origem (BAGGIO; BAGGIO, 2014) até a situação atual do Brasil. Embora o país apresente, desde seus primórdios, vocação empreendedora (CUSTÓDIO, 2011), ainda é recente a dedicação por parte do poder público em incentivar tais iniciativas.

Para compreender a atuação do empreendedorismo no âmbito do ensino, o trabalho seguir apresenta as perspectivas dos Gestores do Campus de Vitória de Santo Antão relação aos seus interesses e incentivos destes profissionais, no tocante às prátic educação empreendedora. O principal intuito do artigo é expor a relação profunda entre um ensino inovador e a autonomia adquirida pelos estudantes, no processo de aprendizagem.

Além de apresentar novos parâmetros profissionais aos alunos, uma proposta de práticas disruptivas, durante a rotina escolar, cria uma aproxi diversas gestões profissionais. 
Mais do que apresentar novos parâmetros profissionais aos alunos, uma vez que o empreendedorismo, durante a rotina escolar, pode se vincular à atuação em empresas juniores e possibilitar uma aproximação cotidiana às gestões profissionais.

Tal finalidade se justifica por funcionar como um modelo de atividade extraclasse cuja aplicabilidade de conceitos teóricos estimula o processo de aprendizagem. Ademais, ocorre uma preocupação no desenvolvimento de habilidades interpessoais e competências voltadas à gestão de pessoas e inovação (PERIARD, 2011).

No tocante à metodologia proposta, foi desenvolvida uma pesquisa de natureza qualitativa e quantitativa que, embora sejam distintas e não superiores entre si (GUNTHER, 2006), possuem suas peculiaridades no tocante à obtenção de dados. Desta forma, com um questionário aplicado com gestores do Instituto Federal de Pernambuco - campus Vitória de Santo Antão, junto a uma abordagem qualitativa dos resultados conseguidos.

\section{FUNDAMENTAÇÃO TEÓRICA}

No referencial teórico, foram propostas as bases bibliográficas para o artigo a que se propõe escrever. Nesta etapa qualitativa, conceitos voltados ao empreendedorismo, bem como a sua tipologia e origem. Além disso, foi estudado como acontece a promoção da educação empreendedora no Brasil e as consequências de tais práticas na sociedade brasileira.

Empreender é um conceito muito debatido na sociedade, uma vez que é ampla a possibilidade de definir tal vocábulo. Um primeiro pensamento é associar o empreendedorismo ao capitalismo, uma vez que é comum escutar a respeito de empreendimentos relacionados a obras suntuosas (RALLO, 2013). Entretanto, o autor explana que é necessário gerar valor para proporcionar lucro a determinado investimento.

A palavra empreendedorismo tem origem latina, com primórdios de escrita “imprendere", evoluindo para o francês, inglês até chegar na versão em língua portuguesa (BAGGIO; BAGGIO, 2014). De acordo com Richard Cantillon, estudioso francês do século XVIII, empreendedor é aquele que corre riscos (CRUZ, 2005).

Neste ponto, todos empreendedores possuem semelhanças, uma vez que é necessário encarar desafios, ter persistência, rede de contatos, proatividade, se antepor aos problemas, entre outras características próprias aos empreendedores, conforme apontam algumas das dez qualidades das pessoas inovadoras (DESAFIO EMPREENDEDOR, 2019).

Para se definir objetivamente, Baggio propõe que: o "empreendedorismo pode ser compreendido como a arte de fazer acontecer com criatividade e motivação $(2014$, p.26)." Na 
mesma linha de pensamento, Santiago (2009) recorda que é necessário solucionar alguma dor de um cliente, isto é, o autor sugere a resolução de um problema social, econômico ou até pessoal existente.

É possível encontrar empreendedores em diversas áreas, seja numa própria empresa, numa organização pública, numa organização de terceiros ou em organizações sociais (BAGGiO; BAGGIO, 2014). Já Vale, Corrêa e dos Reis (2014) recordam as duas possibilidades de se empreender, seja por necessidade ou oportunidade.

Com essa visão ampla, é possível recordar a grande vertente inovadora presente na sociedade brasileira. De acordo com Custódio (2011), o Brasil depende de sua população empreendedora. Já desde o século XIX, com Barão de Mauá, a nação se desenvolve sob liderança de pessoas com senso de disruptividade.

Entretanto, Custódio (2011) ainda recorda que o poder público necessita incentivar de forma mais efetiva ações inovadoras. Apenas após a década de 1990 e com grande parcela de apoio do Serviço Brasileiro de Apoio à Micro e Pequena Empresa, o SEBRAE, que houve maior capacitação aos pequenos e nascentes negócios no país. Já Bona (2019) aponta que é presente, nos últimos anos, encontrar indivíduos voltados ao empreendedorismo e há incentivo por parte do poder público, inclusive a partir da participação de prêmios a nível internacional.

Com intuito de se tornar mais partícipe da globalização, processo que valoriza a tecnologia, é crescente o número de startups ao redor do mundo, inclusive no Brasil (MATTIAZZI, 2020). Isto justifica um fato interessante: de acordo com a última pesquisa realizada, aproximadamente $38 \%$ da população nascida brasileira têm vocação à abertura de novos negócios, segundo o Global Entrepreneurship Monitor, junto ao SEBRAE (2018).

\section{METODOLOGIA}

Este artigo acadêmico expõe, discute, analisa e promove questões voltadas empreendedorismo entre os servidores públicos que ocupam posição de destaque e gestão no Instituto Federal de Educação, Ciência e Tecnologia de Pernambuco - campus Vitória de Santo Antão.

A instituição de ensino citada acima foi fundada em 1954, com o nome de Escola de Magistério de Educação Rural e Doméstica, com intuito de formar estudantes para o mercado profissional. Desde 2008, faz parte da rede de Institutos Federais do Brasil, com cursos superiores, técnicos integrados, além dos profissionalizantes. Com aproximadamente mil 
alunos, o local funciona como escola agrícola e também abriga estudantes como residentes (FERREIRA, 2015).

Para explicar a divisão de procedimento metodológico, é necessário compreender que foi realizado um estudo prévio visando ao aprofundamento de conceitos expostos no referencial teórico, tais como origem e conceitos de empreendedorismo, como o Brasil se comporta perante à inovação e como a população brasileira reage à criação de novos negócios, além de outros assuntos a serem debatidos nos resultados e discussões.

Quanto ao método utilizado, buscou-se uma abordagem mista, tendo uma parte qualitativa e outra quantitativa. Gunther (2006) explica que, embora não haja melhor ou pior categoria de pesquisas, há diferenças entre ambas. Gil (2002) compreende o método quantitativo como aquele que se desenvolve com um recorte e levantamento de dados a partir de tratamento dos mesmos. Já a visão qualitativa, prevê "observação, reflexão e interpretação à medida que a análise progride (p. 90).”

Richardson (1999), no que diz respeito à coleta de resultados, explica que esta é uma atividade inerente à ciência, enquanto Oliveira (2009) entende que há significativa necessidade em aplicar a interpretação de resultados conseguidos, algo que nomeia por interpretacionismo.

A pesquisa foi realizada, em campo, com 12 servidores federais, divididos entre gestores educacionais e administrativos, sendo que, dentre o universo escolhido foi entre professores e funcionários públicos com disponibilidade para responder às perguntas no dia da visita técnica. Vale ressaltar que, pela visita ter sido realizada em um dia, buscou-se contactar os principais gestores de cursos, bem como professores com possíveis afinidades na questão do emrpeendedorismo, como as áreas de extensão e direção geral.

O instrumento de coleta de dados possuiu 19 questões, divididas entre duas seções: na primeira etapa, figuravam questões quanto ao aspecto pessoal e de formação, com indagações a respeito de gênero biológico, etnia, formação profissional, entre outras perguntas. Já segunda parte, contou com interrogações sobre o conhecimento, experiência, participaçã̃o prévia em ações empreendedoras, bem como a importância de educação voltada à inoyação em locais de aprendizado, em um local da rede pública federal, caso da escola em estudo.

\section{RESULTADOS E DISCUSSÃO}

O estudo realizado com os gestores do Campus Vitória de Santo Antão consistiu em um questionário com a abordagem metodológica qualitativa e quantitativa. Foram realizadas, 
no total, doze entrevistas com os gestores. Desse modo buscou-se traçar o perfil dos gestores de ensino. Além disso, foram realizadas dezenove perguntas, nas quais catorze foram fechadas e cinco abertas.

A primeira parte do formulário, consistiu em perguntas pessoais sobre os entrevistados apresentadas no início da pesquisa, a finalidade era coletar dados a respeito do sexo biológico dos indivíduos. No total sete pessoas que se identificam como sexo biológico masculino e cinco como sexo biológico feminino, a indicação do mesmo está representado no gráfico 1.

Com o intuito de compreender melhor quem são esses gestores em seu âmbito individual, apresenta-se a informação que, quanto ao sexo biológico, 58,3\% são masculinos, enquanto $41,7 \%$ são biologicamente mulheres.

Figura 1: Sexo biológico dos entrevistados.

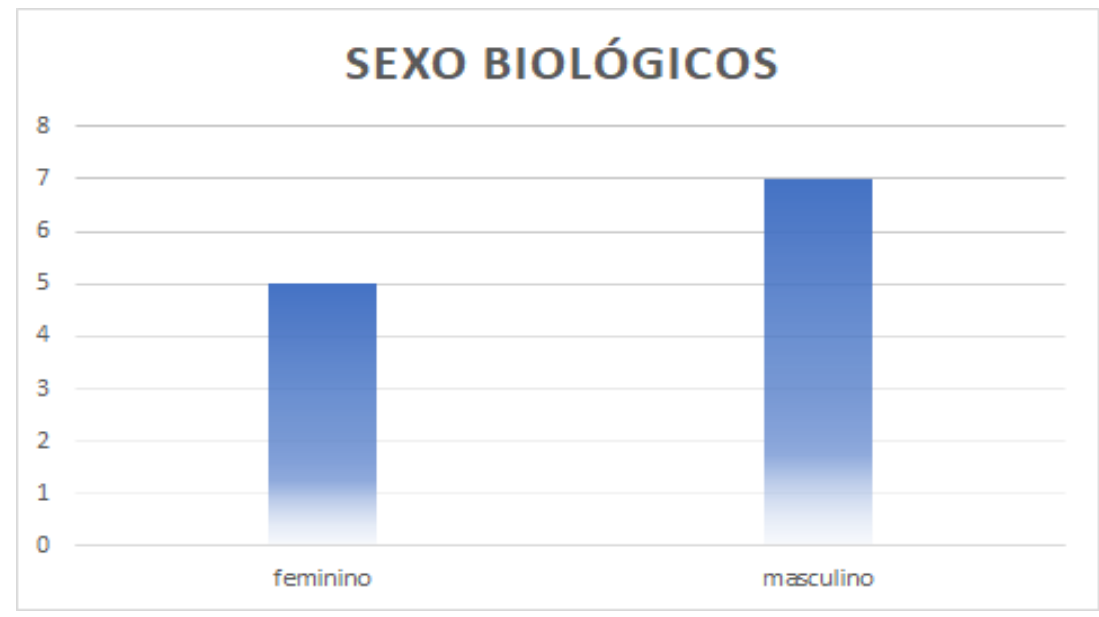

Fonte: Própia (2020).

A segunda pergunta da entrevista aos gestores do Campus Vitória de Santo Antão, conforme abaixo o gráfico 2 , aborda a referência cor/etnia e constata que $8,3 \%$ dos gestores se identificam enquanto pretos, colocando em questão a realidade racial.

Segundo Ribeiro, a autora discute que "se a população negra é maioria no país, quase $56 \%$, o que torna o Brasil a maior nação negra fora da África, a ausência de pessoas negras em espaços de poder deveria ser algo chocante (2019, p.32)". 
Figura 2: Cor/Etnia dos entrevistados.

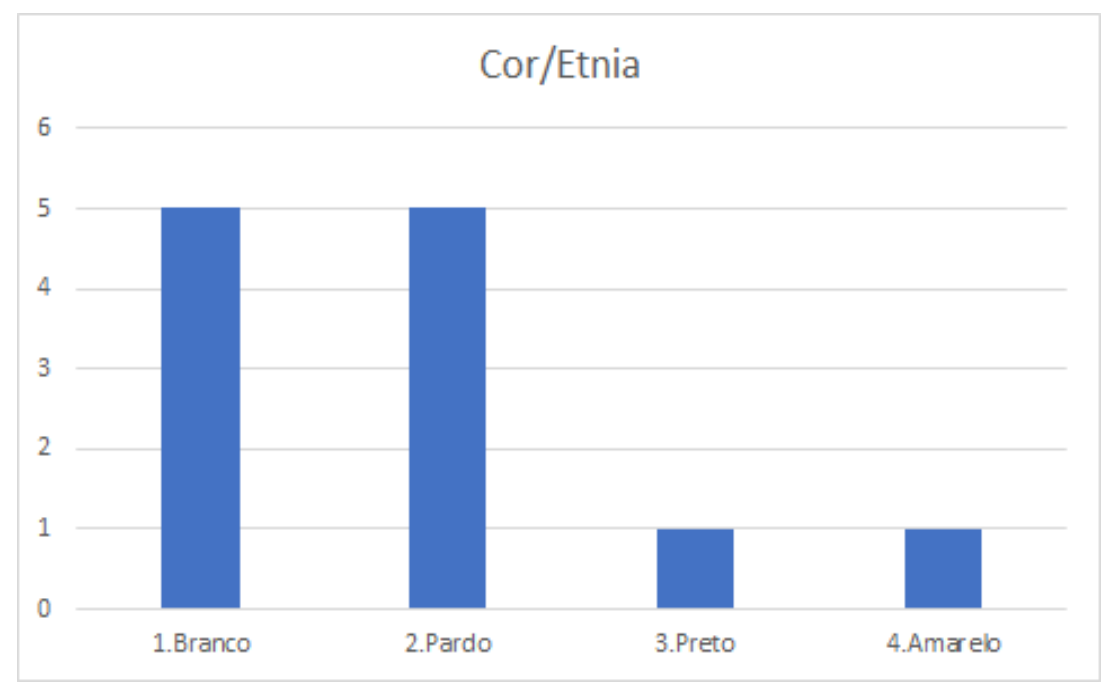

Fonte: Própria (2020).

Analisando também os dados foi verificada a qualificação profissional dos gestores, na qual $16,7 \%$ não possuem pós-graduação, e 83,3\% possuem algum tipo de pós-graduação dentre elas: doutorado acadêmico, mestrado acadêmico, especialização e mestrado profissional.

Figura 3: Gráfico referente a pós-graduação dos entrevistados.

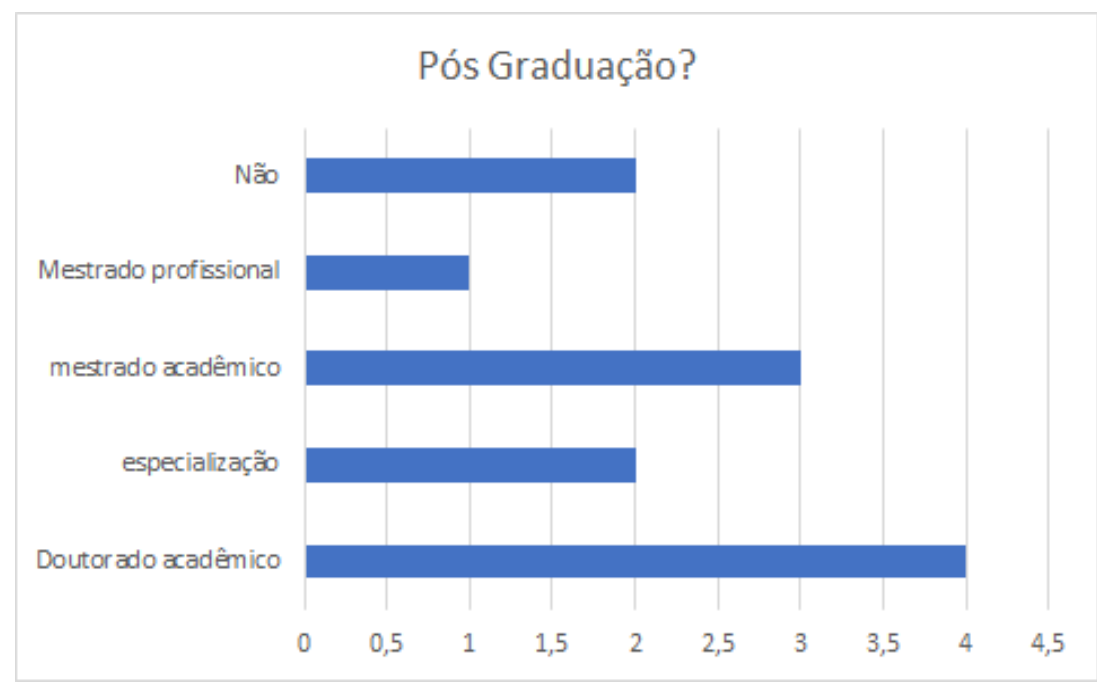

Fonte: Própria (2020)

Tal fato indica um cenário de profissionais que, embora representem um quadro social distinto, buscam constantemente conhecimento e qualificações profissional. Servidores federais de ensino, desta forma, possuem maiores condições de promover a democratização do ensino de acordo com as funções que ocuparem. Zientarski e Pereira (2009) explicam que expandir os saberes múltiplos para mais pessoas foi possível graças a movimentos sociais de docentes, em períodos das décadas de 1970 e 1980. 
$\mathrm{Na}$ seguinte interrogação, procura-se entender se os gestores conheciam ou conseguiam identificar ações empreendedoras no campus Vitória de Santo Antão. Ao todo, quatro pessoas conhecem ações empreendedoras e oito não possuem conhecimento acerca dessas ações. A figura 3 apresenta a porcentagem dessa informação.

Em seguida, contemplando o mesmo assunto referente a pergunta aberta aos entrevistados que reconheceram ações empreendedoras, foram questionados sobre quais ações existentes no Instituto. Algumas respostas foram: alunos agricultores vendem seus produtos, Semana Nacional de Ciência e Tecnologia, projetos de extensão e PDVAGRO (Programa despertando Vocações Agrárias).

Gráfico 4: Reconhecimento de ações empreendedoras no campuspor parte dos gestores.

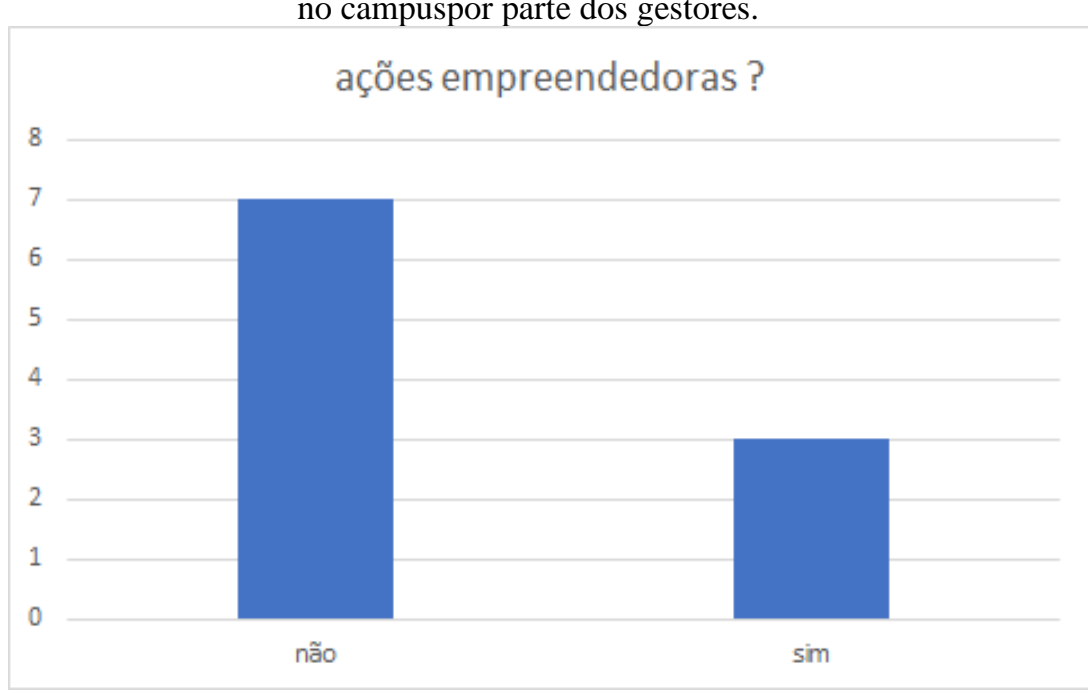

Fonte: Própria (2020).

O reconhecimento destas ações no Campus é diretamente relacionável ao que propõe Alves (2011), já que o empreendedor, conforme o autor, é aquele que empreende ou se aventura à realização de tarefas difíceis, já o empresário, objetiva lucro, investe em capital.

Em questão, o conceito de empreender não existe enquanto regra de obtenção de lucro, mas sim enquanto um "comportamento empreendedor" (ALVES, 2011, p.15), visto que, um dos momentos de integração dos alunos a serem socializados a este comportamento é na participação da semana da ciência e tecnologia, projetos de extensão, PDVAGRO (Programa despertando Vocações Agrárias) e também quando alunos agricultores vendem seus produtos. 
Gráfico 5: Conhecimento dos gestores sobre o PDV.

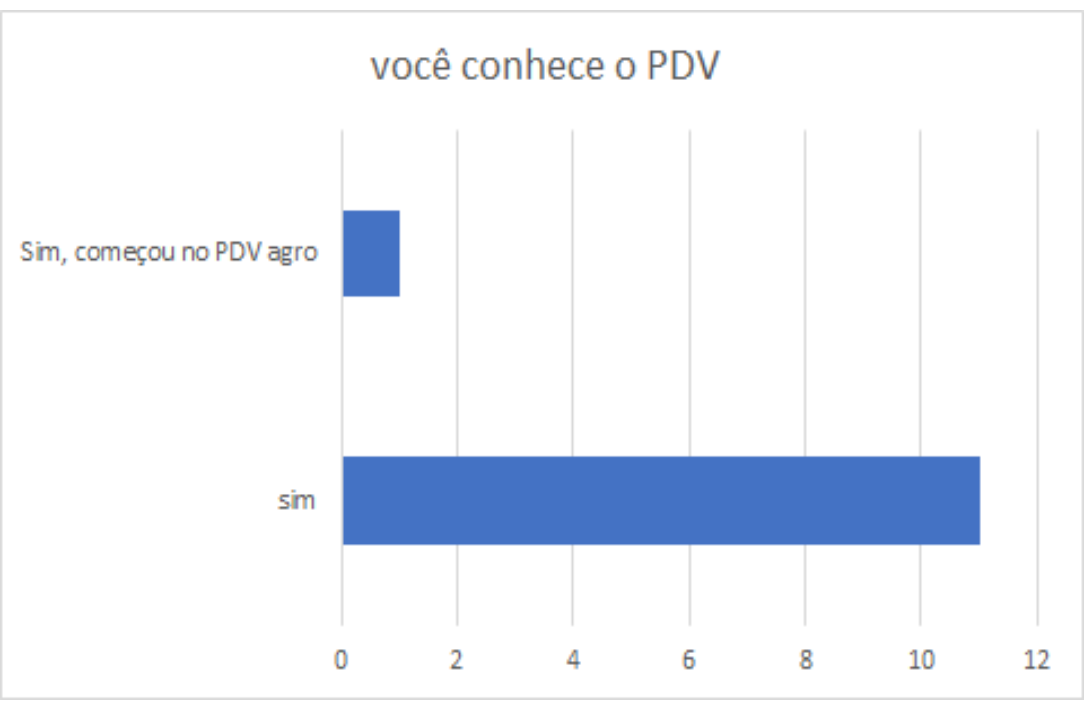

Fonte: Própria (2020).

É interessante observamos que de acordo com a figura 5, representada pela décima nona questão do questionário, três pessoas não conhecem o Programa Despertando Vocações (PDV) e nove conhecem. Entretanto desse total quatro pessoas identificou o PDV como uma ação empreendedora.

Notando que cinco pessoas não destacam o PDV como uma ação empreendedora e em busca de possibilitar que esses profissionais modifiquem suas práticas para atuar com o empreendedorismo no ensino aprendizagem, é importante que o referido programa permaneça contribuindo em estudos e em iniciativas que apoiem tais perspectivas de ensino. Desta forma, é possível conseguir construir uma identidade mais forte a partir dessa temática, para que seja possível que se dinamize a relação do foco empreendedor no interior deste movimento em prol da extensão, com seu alcance externo entre instituições de ensino. Costa (2015, p.29), inclusive, explana "atividades como as descritas como práticas inovadoras em educação".

Outra temática estudada diz respeito às empresas juniores, que contribuem para a prática do "comportamento empreendedor" (ALVES, 2011, p.15). Atribuiu-se, pois, questionário o interesse em compreender se os gestores do campus possuem conhecimento sobre o conceito das empresas juniores, além de saber se são favoráveis à existência desta categoria na instituição de ensino e se conhecem algum exemplar externo. 
Figura 6: Conhecimento dos gestores sobre empresa júnior.

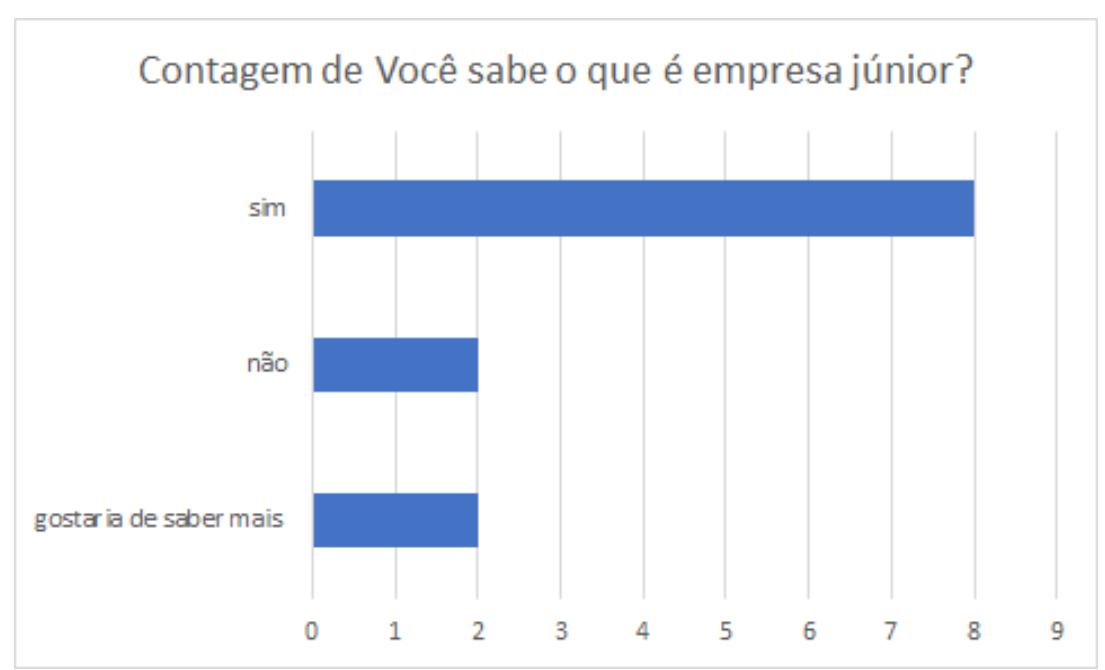

Fonte: Própria (2020).

É importante explicar também um pouco sobre a origem e conceito de empresas juniores, a fim de ilustração do assunto. Surgida em 1967, sem fins lucrativos (CATI JR, 2017), as empresas juniores, de acordo com Periard (2011), são gerenciadas e organizadas por próprios estudantes de cursos superiores.

No total, foram oito respostas afirmando saber o que é uma empresa júnior e dois indivíduos alegaram não saber sobre o tema, sendo que ao perguntar se são favoráveis à existência de uma empresa junior no interior do campus, todos os entrevistados se apresentaram a favor. Essa representação favorável enquanto que 2 indivíduos desejam saber mais e outros 2 desconhecem seu significado implicam em uma problemática: há uma necessidade em ampliar a função das empresas juniores dentro do âmbito de ensino, visto que, sua atuação tem influenciado no protagonismo das universidades brasileiras.

Figura 7: Conhecimento dos gestores sobre empresas juniores

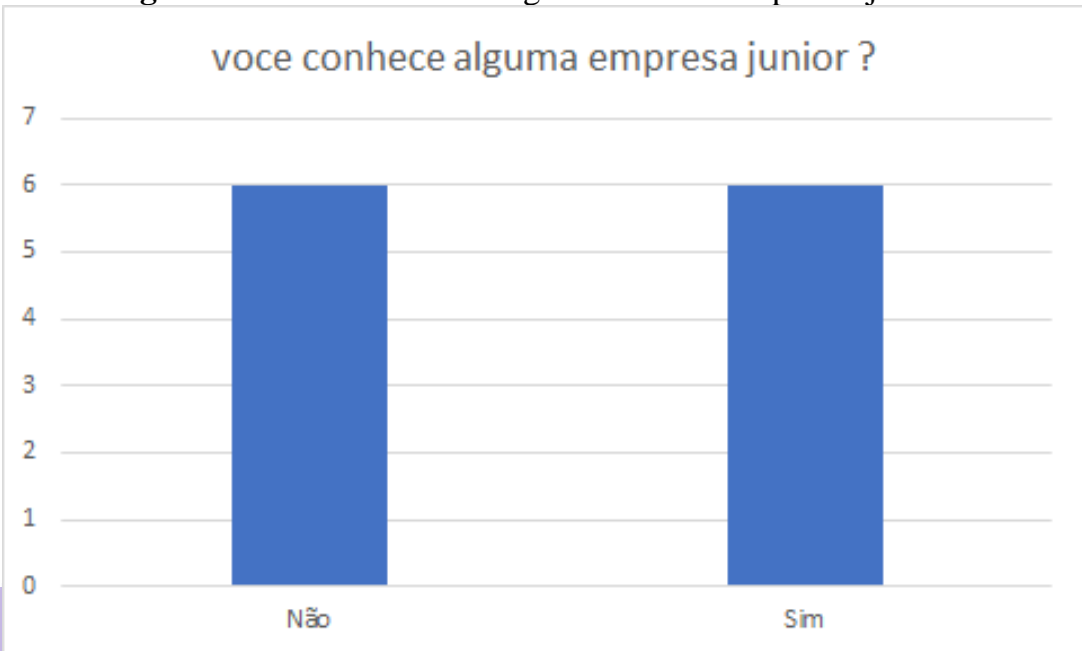

Fonte: Própria (2020) 
Um exemplo da importância de se fomentar as empresas juniores nas escolas brasileiras é a lei $\mathrm{n}^{\circ} 13.267$, a qual regulamentou o funcionamento das mesmas perante instituições de ensino superior.

Atuar em empresas juniores para estudantes em período de graduação é útil para o desenvolvimento individual dos mesmos. Americano (2020) explica que o horizonte individual das redes de contato, junto às experiências adquiridas, fomentam um profissional mais aprimorado ao mercado de trabalho ao qual será inserido futuramente.

Ressaltando que $50 \%$ dos gestores conhecem alguma empresa júnior a partir do gráfico abaixo, e ressaltando que elas promovem ações empreendedoras, pode-se pontuar seu fundamento enquanto educação empreendedora na instituição de ensino. Desta forma se faz necessário que a essa outra metade, seja possível apresentar não só as empresas juniores, mas também outras ações inovadoras para a educação, tais como a gamificação ou STEAM (Science, Technology, Engineering, Math). Pinto (2019) justifica a disruptividade destas ações pelo fato de facilitar o ensino com jogos lúdicos.

Ao serem perguntados quanto a possuir experiência com empreendedorismo 58\% dos que responderam o questionário não possuem nenhum tipo de experiência. Levando em consideração os dados anteriormente apresentados na figura 3 (Gráfico referente a pósgraduação entre os gestores) revela que apesar de 83,3\% possuírem alguma qualificação profissional de pós-graduação, a maioria dos entrevistados não tiveram contato nem empírico, nem científico com ações empreendedoras de ensino.

A partir dessa perspectiva é válido destacar que para conseguir aplicar atividades extraclasse e alcançar uma inovação de ensino que aborda uma perspectiva empreendedora é preciso partir da virtude de repensar mecanismos promotores da qualificação desses gestores em ampliar o conhecimento dos mesmos acerca de empreendedorismo. Apenas com mais aprofundamento do tema é possível pensar na educação empreendedora e autonomia estudantil (NOEMI, 2018). 
Figura 8: A respeito da experiência dos gestores com empresa júnior e empreendedorismo

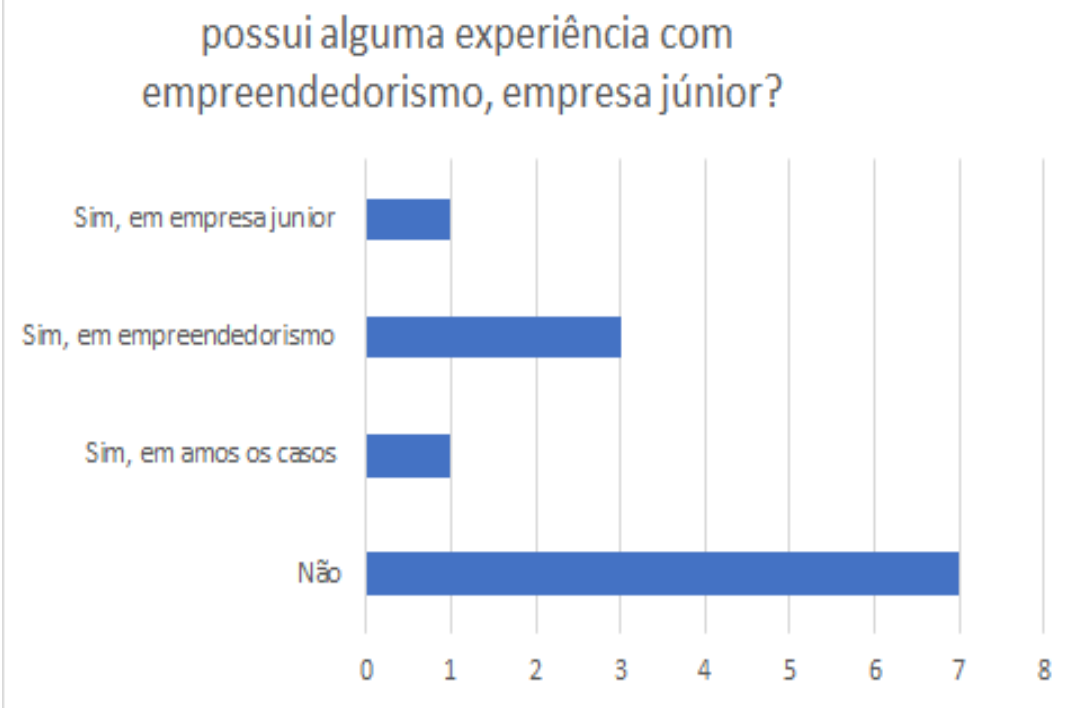

Fonte: Própria (2020)

\section{CONCLUSÃO}

Este estudo acadêmico teve como foco a realização de uma pesquisa com gestores do Instituto Federal de Educação, Ciência e Tecnologia de Pernambuco, cuja natureza do instrumento de coleta de dados foi quantitativa e qualitativa. O questionário aplicado possui dezenove questões, com doze entrevistados. Desta maneira, foram obtidos pensamentos a respeito de empreendedorismo, empresas juniores, apoio a ações empreendedoras e atuação em ações inovadoras por parte dos respondentes no Campus Vitória de Santo Antão, do IFPE.

Como relatado no gráfico 4, o qual trata da percepção de mais da metade dos gestores, sendo sete dos doze voluntários da pesquisa, é o desconhecimento de ações empreendedoras no Campus agrícola em questão. No entanto, o gráfico 5 expõe que os funcionários públicos alegam perceber a existência do Programa Despertando Vocações - Ciências Agrárias, em sua maioria, já que onze respondents conhecem a iniciativa. Ressalta-se que tal programa ocupa papel diferenciado na promoção de atividades voltadas à pesquisa, ao ensino e à extensão, sendo uma possibilidade de se inovar em instituições de ensino.

O diferencial deste trabalho acadêmico, então, está no entendimento da forma pela qual o empreendedorismo se sucede em instituições de ensino, além da contribuição científica com aprofundamento sobre o tema empreendedorismo.

\section{REFERÊNCIAS}

AMERICANO, C. M. F. A importância das empresas juniores para o início da carreira $[185]$ 
profissional. Disponível em: https://ufmsjr.ufms.br/a-importancia-das-empresas-juniorespara-o-inicio-da-carreira-profissional/ Acesso em: 15 de setembro de 2020.

BAGGiO, A. F.; BAGGiO, D. K. Empreendedorismo: Conceitos e Definições. Rev. de Empreendedorismo, Inovação e Tecnologia. v. 1, n. 1, p. 25- 38, 2014.

BRASIL. Lei $n^{\circ}$ 13267, de 6 de abril de 2016. Disciplina a criação e a organização das associações denominadas empresas juniores, com funcionamento perante instituições de ensino superior. Diário Oficial da União, Brasília, DF, p. 1-74, 6 abr. 2016.

CATI JR. A história do movimento empresa júnior. Disponível em: https://medium.com/@ catijr/a-hist\%C3\%B3ria-do-movimento-empresa-junior-5f02a2c9fd37 $\begin{array}{llllll}\text { Acesso } & \text { em: } & 10 & \text { de } & \text { outubro } & \text { de }\end{array}$

CRUZ, C. F. Os motivos que dificultam a ação empreendedora conforme o ciclo de vida das organizações. Um estudo de caso: Pramp's lanchonete. 2005. 125 p. Dissertação (Mestrado), Programa de Pós-Graduação em Engenharia de Produção, Universidade Federal de Santa Catarina, Florianópolis, 2005.

COSTA, P. da. Gestão Escolar, Empreendedorismo e Liderança na Perspectiva Educacional. Lajeado - RJ, 2015. 73 p. Monografia (Centro Universitário Univates) Curso de Pedagogia, Centro Universitário Univates, 2015.

CUSTÓDIO, T. P. A importância do empreendedorismo como estratégia de negócios: Fênix Locações e Eventos Guaiçar. SP. Lins - SP, 2011. 62 p. Monografia (Centro Universitário Católico Auxilium) Curso de Administração, UNISALESIANO, 2011.

DESAFIO EMPREENDEDOR. As 10 características empreendedoras da ONU trabalhadas no desafio empreendedor. Disponível em: https://desafioempreendedor.com.br/as-10-caracteristicas-empreendedoras-da-onutrabalhadas-no-desafio-empreendedor/ Acesso em: 16 de setembro de 2020.

FERREIRA, H. O campus. Disponível em: https://portal.ifpe.edu.br/campus/vitoria/ocampus Acesso em: 16 de setembro de 2020.

GUNTHER, H. Pesquisa qualitativa versus pesquisa quantitativa: esta é a questão? Psicologia Teoria e Pesquisa. v. 22, n. 3, p. 201 - 210, 2006.

IDV. Instituto IDV. Disponível em: https://institutoidv.org/sobre/ Acesso em: 15 de setembro de 2020.

MATTIAZZI, D. Número de startups no Brasil aumentou 20 vezes nos últimos oito anos; 11 já são unicórnios. Disponível em: https://g1.globo.com/globonews/noticia/2020/01/15/numero-de-startups-no-brasil-aumentou20-vezes-nos-ultimos-oito-anos-11-ja-sao-unicornios.ghtml Acesso em: 16 de setembro de 2020.

NOEMI, D. Veja o que é educação empreendedora e como aplica-la em sala de aula. Disponível em: https://escolasdisruptivas.com.br/escolas-do-seculo-xxi/educacao- 
empreendedora/ Acesso em: 14 de setembro de 2020.

OLIVEIRA, C. L. Um apanhado teórico-conceitual sobre a pesquisa qualitativa: tipos, técnicas e características. In: Travessias, 2008, Cascavel-PR. Anais: UNIOESTE, 2009.

PERIARD, G. Empresa júnior - o que é e como funciona. Disponível em: http://www.sobreadministracao.com/empresa-junior-o-que-e-e-como-funciona/ Acesso em 11 de outubro de 2019.

PERNAMBUCO (Estado). Secretaria de Ciência, Tecnologia e Meio Ambiente. Empreendedorismo e inserção no mundo do trabalho. In: Recife - PE: SECTMA, 2009. Org: Alexandre Rodrigues Alves. v. 2. p. 108, 2009.

PINTO, D. de O. Gamificação na educação: tudo o que você precisa saber. Disponível em: https://blog.lyceum.com.br/o-que-e-gamificacao-na-educacao/ Acesso em 15 de setembro de 2020.

RALLO, J. R. Capitalistas e empreendedores não exploram nenhum trabalhador. Disponível em: https://www.mises.org.br/Article.aspx?id=1623 Acesso em: 16 de setembro de 2020.

RIBEIRO, D. Pequeno manual antirracista. 1 a ed. — São Paulo : Companhia das Letras, 2019.

RICHARDSON, R. J. Pesquisa social: métodos e técnicas. 3. ed. São Paulo: Atlas, 1999.

SANTIAGO, E. G. Vertentes teóricas sobre empreendedorismo em Schumpeter, Weber e Mcclelland: novas referências para a sociologia do trabalho. Revista de Ciências Sociais, v. 40. n. 2, p. $87-103,2009$.

VALE, G. M. V; CORRÊA, V. C.; REIS, R. F. dos. Motivações para o

Empreendedorismo: necessidade, versus oportunidade? RAC, v. 18, n. 3, p. $311-327$, maio/junho 2014.

ZIENTARSKI, CL.; PEREIRA, S. M. Os caminhos para a democratização no Brasil: qual o papel dos educadores neste processo? Revista HISTEDBR Online, v. 9, n. 34, p. $154-$ 166, jun. 2009. 